\title{
Selective 3,4-Dihydroxyphenylalanine Analysis in Human Urine as Ethoxycarbonyl- tert-butyldimethylsilyl Derivatives by Gas Chromatography-Mass Spectrometry
}

\author{
Man-Jeong Paik, Duc-Toan Nguyen, Jaehwan Yoon, ${ }^{\dagger}$ In-Seon Cho, \\ Wooyoung Shim, ${ }^{\dagger}$ Kyoung-Rae Kim, ${ }^{\ddagger}$ Ki Hong Cho, Sangdun Choi, and Gwang Lee ${ }^{\S, *}$ \\ Department of Molecular Science and Technology, Ajou University, Suwon 443-749, Korea \\ ${ }^{\dagger}$ Biometabolite Analysis Laboratory, College of Pharmacy, Sungkyunkwan University, Suwon 440-746, Korea \\ ${ }^{\ddagger}$ Department of Neurosurgery and Institute for Medical Science, School of Medicine, Ajou University, Suwon 443-721, Korea \\ ${ }^{\S}$ Institute for Medical Science, School of Medicine, Ajou University, Suwon 443-721, Korea. ${ }^{*}$ E-mail: glee@ajou.ac.kr \\ Received September 15, 2010, Accepted January 19, 2011
}

\begin{abstract}
A new analytical method for measurement of 3,4-dihydroxyphenylalanine (DOPA) in human urine was developed. DOPA from an aqueous solution was converted into an ethoxycarbonyl (EOC) derivative. A tertbutyldimethylsilyl (TBDMS) reaction under anhydrous conditions was then attempted for analysis by gas chromatography-mass spectrometry in selected ion monitoring mode. A new mass spectral data on DOPA as a tri-EOC/mono-TBDMS derivative was built. This method showed good linearity $(\mathrm{r} \geq 0.999)$, precision (\% relative standard deviation $=3.1-9.2)$, and accuracy $(\%$ relative error $=-7.2-8.8)$, with a detection limit of 0.05 $\mathrm{ng} / \mathrm{mL}$. This selective and accurate method of DOPA analysis will be useful for biochemical monitoring of various neurological disorders including Parkinson's disease in biological fluids.
\end{abstract}

Key Words : 3,4-Dihydroxyphenylalanine (DOPA), Ethoxycarbonyl/tert-butyldimethylsilyl derivatives, Gas chromatography-mass spectrometry, Urine sample

\section{Introduction}

As a metabolite of tyrosine, 3,4-dihydroxyphenylalanine (DOPA) is consecutively metabolized to catecholamines, such as dopamine, norepinephrine, and epinephrine, ${ }^{1-3}$ which have been suggested as neurotransmitter candidates in the central nervous system. ${ }^{1}$ Thus, accurate measurement of DOPA level in biological fluids of various neurological disorders, including Parkinson's disease, ${ }^{4-7}$ has been useful for biochemical monitoring of disease states.

Analytical methods for detection of DOPA in platelets, plasma, and adrenal glands have been mostly reported by high performance liquid chromatography (HPLC) ${ }^{8-13}$ liquid chromatography-mass spectrometry (LC-MS) or LC-MS/ $\mathrm{MS},{ }^{14-16}$ only a few studies have been performed using gas chromatography (GC) and gas chromatography-mass spectrometry (GC-MS). ${ }^{17-19}$

In GC and GC-MS analysis, derivatization is generally required to block all active protons of hydroxyl, carboxyl, and amine groups present in DOPA, for improvement of its thermal stability and volatility, as well as GC and GC-MS properties.

A variety of derivatization methods based on acylation, ${ }^{18-20}$ or methylation ${ }^{17}$ have been investigated for analysis of DOPA. Among them, trimethylsilyl (TMS) derivatives are unstable under moist conditions; acylation and methylation usually require a clean-up step for removal of excess reagent and side products. ${ }^{17}$

Most of previous reports for DOPA analysis by GC and GC-MS were performed under anhydrous conditions, even though it contains a catechol group and can easily oxidize and decompose in sample preparations. Thus, in this work, we first attempted DOPA analysis in human urine, as in our previous reports. ${ }^{21-23}$ It includes direct conversion as a stable solvent-extractable form by a two-phase ethoxycarbonyl (EOC) derivative with ethyl chloroformate (ECF) in the dichloromethane phase for catechol and amine groups of DOPA in aqueous solution, followed by a tert-butyldimethylsilyl (TBDMS) derivative for carboxylic acid function in anhydrous conditions with $N$-methyl- $N$-(tert-butyldimethylsilyl)trifluoroacetamide (MTBSTFA), which is more stable for moisture and effective MS properties than a TMS derivative in GC-MS analysis using selected ion monitoring (SIM) mode.

\section{Experimental}

Chemicals and Reagents. DOPA, pentadecanoic acid as an internal standard (IS), ECF, and thiodipropionic acid (TDPA) were purchased from Sigma-Aldrich (St. Louis, MO, USA). Toluene, diethyl ether, ethyl acetate, and dichloromethane (pesticide grade) were obtained from Kanto Chemical (Tokyo, Japan). MTBSTFA was obtained from Pierce (Rockford, IL, USA). Sulfuric acid and sodium hydroxide were supplied by Duksan (Kyungkido, South Korea). All other chemicals were of analytical reagent grade.

Preparation of Standard Solutions. A standard stock solution of DOPA was prepared at $10 \mathrm{mg} / \mathrm{mL}$ in $0.1 \mathrm{M} \mathrm{HCl}$ containing $0.2 \%$ TDPA as an antioxidant. Working standard solutions at different concentrations, $100,10,1.0$, and 0.1 $\mu \mathrm{g} / \mathrm{mL}$ were prepared by dilution of stock solution with the same solvent. The IS working solution of $1.0 \mu \mathrm{g} / \mathrm{mL}$ was 
made up from the stock solution at $10 \mathrm{mg} / \mathrm{mL}$ in toluene. The calibration curve was constructed by spiking standard to human urine with six different amounts in the range of 1-100 $\mathrm{ng} / \mathrm{mL}(1,5,10,20,50$, and $100 \mathrm{ng} / \mathrm{mL})$, each containing 50 $\mathrm{ng} / \mathrm{mL}$ of IS. All standard solutions were stored at $4{ }^{\circ} \mathrm{C}$.

Gas Chromatography-Mass Spectrometry. GC-MS analyses in SIM mode were performed using an Agilent 6890N gas chromatograph connected to an Agilent 5975B massselective detector $(70 \mathrm{eV}$, electron ionization mode), and installed with an Ultra-2 (5\% phenyl-95\% methylpolysiloxane bonded phase; $25 \mathrm{~m} \times 0.20 \mathrm{~mm}$ I.D., $0.11 \mu \mathrm{m}$ film thickness) cross-linked capillary column (Agilent Technologies, Atlanta, GA, USA). Temperatures of the injector, interface, and ion source were 260,300 , and $230{ }^{\circ} \mathrm{C}$, respectively. Helium was used as the carrier gas, at a flow rate of $0.5 \mathrm{~mL} / \mathrm{min}$ in constant flow mode. Samples were introduced in split-injection mode (10:1), and the oven temperature was set initially at $150{ }^{\circ} \mathrm{C}(1 \mathrm{~min})$, then rose to $200{ }^{\circ} \mathrm{C}$ at $30{ }^{\circ} \mathrm{C} / \mathrm{min}$, and was finally programmed to $300{ }^{\circ} \mathrm{C}$ (3 min) at a rate of $20^{\circ} \mathrm{C} / \mathrm{min}$. In SIM mode, three characteristic ions for each of DOPA and IS were selected for peak identification, and all measurements were prepared in triplicates (Table 1).

EOC-TBDMS Reaction and Method Validation for Urinary DOPA Analysis. Spiked pooled human urine samples including DOPA $(20 \mathrm{ng} / \mathrm{mL})$ and IS $(50 \mathrm{ng} / \mathrm{mL})$ were used to investigate optimal conditions. Each spiked pooled human urine sample was subjected to EOC reaction, with a sequential TBDMS reaction, as described elsewhere. ${ }^{14-16}$ Briefly, the first step of the two-phase EOC reaction was performed by vortex-mixing $(10 \mathrm{~min})$ in an aqueous phase $(1.0 \mathrm{~mL}$ of sodium phosphate buffer $\mathrm{pH} 7.5)$ containing standards with ECF $(50 \mu \mathrm{L})$ in dichloromethane phase $(1.0 \mathrm{~mL})$, subsequently vortex-mixing $(5 \mathrm{~min})$ after addition of $1.0 \mathrm{M}$ sodium hydroxide $(50 \mu \mathrm{L})$ and $10 \% \mathrm{ECF}$ present in the dichloromethane phase $(200 \mu \mathrm{L})$. Following the $\mathrm{EOC}$ reaction, the aqueous phase was acidified to $\mathrm{pH} \leq 2$ with $10 \%$ sulfuric acid solution, and the reaction mixture was extracted twice with diethyl ether $(3 \mathrm{~mL}$ and $2 \mathrm{~mL})$. Combined extracts were evaporated to dryness under a gentle stream of nitrogen $\left(40{ }^{\circ} \mathrm{C}\right)$. The residue was added with MTBSTFA $(20 \mu \mathrm{L})$ as a silylation reagent and toluene $(20 \mu \mathrm{L})$ as a solvent, and was reacted $\left(60^{\circ} \mathrm{C}\right.$ for $\left.30 \mathrm{~min}\right)$ for GC-SIM-MS analysis.

IS $(50 \mathrm{ng} / \mathrm{mL})$ was spiked into pooled human urine sample of $1 \mathrm{~mL}$ including each six different concentration (1.0 to $100 \mathrm{ng} / \mathrm{mL}$ ) for calibration and the EOC derivative sequential TBDMS reaction was performed in the same manner described above. All samples were individually prepared in triplicate and were analyzed on the same day for assessment of precision, accuracy, and linearity.

The calibration curve constructed from peak area ratios against increasing concentration ratios, in a range of 1.0-100 $\mathrm{ng} / \mathrm{mL}$ from triplicate measurements; correlation coefficients $(r)$ were obtained by linear regression analysis. Intraand inter-day precision (three different days) and accuracy of the method, which were calculated as relative standard deviation (\% RSD) and relative error (\% RE), respectively, were determined from calibration samples at three different concentrations of DOPA.

The limit of detection (LOD) for DOPA was estimated based on the lowest concentration giving a signal greater than the sum of the mean blank signal plus three times the standard deviation of the blank signal obtained via three blank measurements.

For stability testing, DOPA derivative $(5,10$ and $20 \mathrm{ng} /$ $\mathrm{mL}$ ) stored at $4{ }^{\circ} \mathrm{C}$ was measured for 14 days, which was evaluated as peak area ratio of DOPA to IS.

Sample Preparation for Assay of DOPA in Human Urine. 12 Human urine samples, aged 34-36 years, were collected in the morning from healthy males. Urine samples of $1 \mathrm{~mL}$ containing $50 \mathrm{ng} / \mathrm{mL}$ of IS were subjected to the EOC reaction, extraction with diethyl ether, and sequential TBDMS reaction, as mentioned above, prior to GC-SIMMS analysis.

\section{Results and Discussions}

MS Property of DOPA as an EOC-TBDMS Derivative and Optimized SIM Conditions. The electron impact ionization (EI) mass spectrum of DOPA as a tri-EOC/ mono-TBDMS derivative was newly built (Fig. 1). In this spectrum, characteristic fragment ions of $[\mathrm{M}-15]^{+}$and $[\mathrm{M}-$ 57] $]^{+}$were formed by loss of $\mathrm{CH}_{3}$ and $\mathrm{C}\left(\mathrm{CH}_{3}\right)_{3}$, respectively. The prominent $[\mathrm{M}-146]^{+}$ion at $\mathrm{m} / \mathrm{z} 381 \mathrm{might}$ be produced by cleavage of $\mathrm{O}-\mathrm{TBDMS}$ and $\mathrm{CH}_{3}$ from a molecular ion. The recognizable molecular ion of IS as mono-TBDMS derivative was $\mathrm{m} / \mathrm{z} 356$. The ideal IS for accurate measurement of DOPA in biological samples is deuterated DOPA. However, our laboratory doesn't have deuterated DOPA. Thus, in this study, pentadecanoic acid was used as IS, which was satisfactory for rapid and accurate quantification of DOPA although IS as saturated fatty acid was not similar structure by comparison with DOPA. And SIM ions were very useful for selective and specific peak confirmation and quantification of DOPA without major background and interference in urine (Fig. 1).

Method Validation and Urinary DOPA Level in Human. The present method was linear $(r \geq 0.999)$ at a range of 1.0-

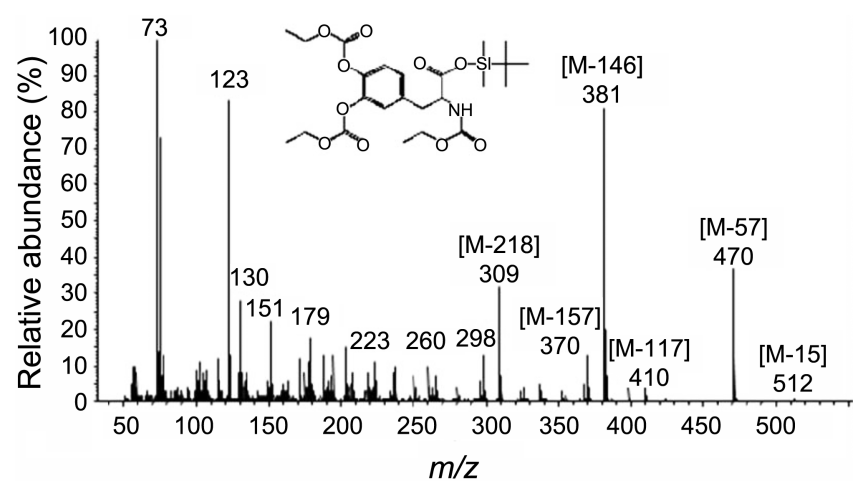

Figure 1. Electron impact ionization mass spectrum of DOPA as a tri-EOC/mono-TBDMS derivatives. 
Table 1. Validation in urinary DOPA analysis as EOC/TBDMS derivative by GC-SIM-MS

\begin{tabular}{|c|c|c|c|c|c|c|c|c|}
\hline \multirow{2}{*}{ Compound } & \multirow{2}{*}{$\begin{array}{l}\text { Selected ion } \\
(\mathrm{m} / \mathrm{z})\end{array}$} & \multirow{2}{*}{$\begin{array}{c}\text { Linearity }^{a} \\
r\end{array}$} & \multirow{2}{*}{$\begin{array}{c}\mathrm{LOD}^{b} \\
(\mathrm{ng} / \mathrm{mL})\end{array}$} & \multirow{2}{*}{$\begin{array}{c}\mathrm{LOQ}^{c} \\
(\mathrm{ng} / \mathrm{mL})\end{array}$} & \multirow{2}{*}{$\begin{array}{c}\text { Added } \\
(\mathrm{ng} / \mathrm{mL})\end{array}$} & \multicolumn{2}{|c|}{ Precision (\% RSD) } & \multirow{2}{*}{$\frac{\text { Accuracy }}{(\% \mathrm{RE})}$} \\
\hline & & & & & & Intra day & Inter day & \\
\hline \multirow[t]{3}{*}{$\mathrm{DOPA}^{d}$} & $\mathbf{3 8 1}, 382,470$ & 0.9992 & 0.05 & 0.2 & 5 & 3.1 & 9.2 & -5.1 \\
\hline & & & & & 10 & 3.1 & 6.8 & -7.2 \\
\hline & & & & & 20 & 3.9 & 7.3 & 8.8 \\
\hline
\end{tabular}

Pentadecanoic acid (IS) ${ }^{e} \quad \mathbf{2 9 9}, 300,341$

Ultra-2 capillary column $\left(25 \mathrm{~m} \times 0.20 \mathrm{~mm}\right.$ I.D., $\left.0.11 \mu \mathrm{m} \mathrm{d}_{\mathrm{f}}\right)$, was initially set at $150{ }^{\circ} \mathrm{C}(1 \mathrm{~min})$, programmed to $200{ }^{\circ} \mathrm{C}$ at $30{ }^{\circ} \mathrm{C} / \mathrm{min}$ then rose to $300{ }^{\circ} \mathrm{C}$ $(3 \mathrm{~min})$ at $20^{\circ} \mathrm{C} / \mathrm{min}$ in SIM mode. Bold ions were selected for quantification. ${ }^{a}$ Correlation coefficient in the calibration range of $1-100 \mathrm{ng} / \mathrm{mL}$ for standard spiked in $1 \mathrm{~mL}$ urine. ${ }^{b} \mathrm{LOD}$, limit of detection. ${ }^{c} \mathrm{LOQ}$, limit of quantification. ${ }^{d}$ As tri-EOC/mono-TBDMS derivatived. ${ }^{e}$ As mono-TBDMS derivative. All measurements were prepared in triplicate.

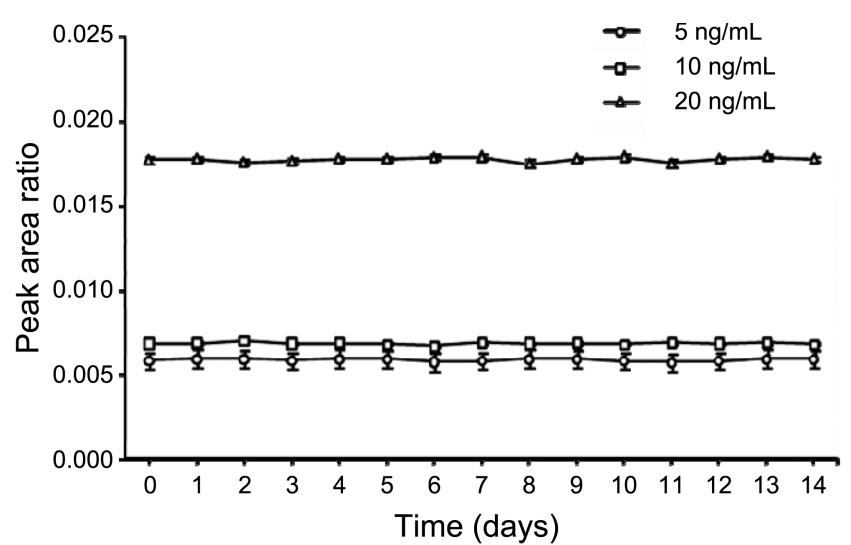

Figure 2. Stability test of DOPA as a tri-EOC/mono-TBDMS derivatives.

$100 \mathrm{ng} / \mathrm{mL}$, with lower LOQ of $0.16 \mathrm{ng} / \mathrm{mL}$ in comparison to methods reported elsewhere including HPLC and LC$\mathrm{MS} / \mathrm{MS}^{8,10,11,13-16}$ except for HPLC method with fluorescence detection. ${ }^{9}$ Intra- (\% RSD = 3.1-3.9) - and inter day precision $(\% \mathrm{RSD}=6.8-9.2)$ and accuracy $(\% \mathrm{RE}=-7.2-$ $8.8)$ at three different levels $(5,10$ and $20 \mathrm{ng} / \mathrm{mL})$ were suitable for quantitative assay of DOPA in biological samples (Table 1). A refrigerated EOC-TBDMS derivatives of DOPA was stable for at least 14 days (Fig. 2). Overall peak area ratios were not statistically significant.

SIM chromatograms of DOPA in normal human urine and
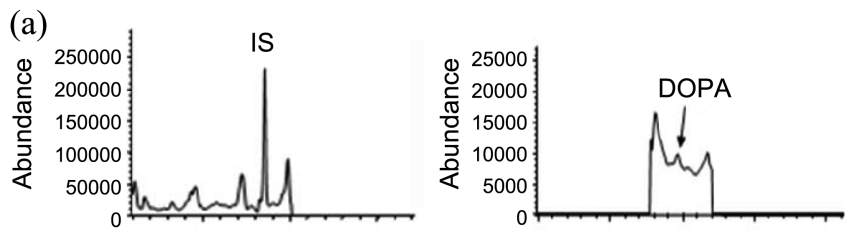

(b)
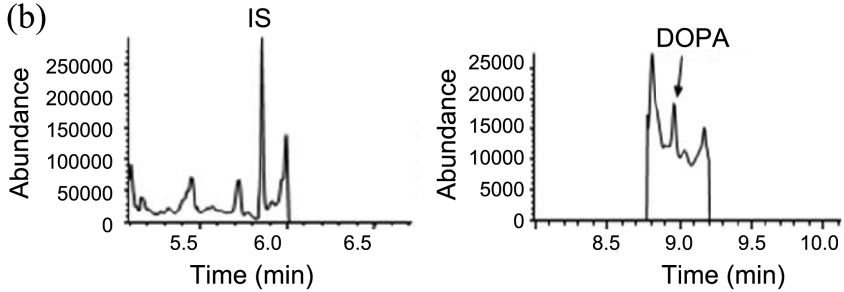

Figure 3. SIM chromatograms of human urine (A) and human urine spiked with $20 \mathrm{ng} / \mathrm{mL}$ of DOPA standard (B). normal human urine spiked with DOPA of $20 \mathrm{ng} / \mathrm{mL}$ are shown in Figure 3. Urinary DOPA level was $11.2 \pm 2.5 \mathrm{ng} /$ $\mathrm{mL}$, which was similar to that of values reported in the literature. ${ }^{24-26}$

\section{Conclusion}

The present GC-SIM-MS method is selective and accurate for measurement of DOPA as a neurotransmitter candidate after the EOC-TBDMS reaction in urine samples. Thus, it will be useful for biochemical monitoring and screening of disease states in human urine.

Acknowledgments. This work was supported by National Research Foundation of Korea Grant funded by the Korean Government (KRF-2008-314-E00183 to M.P.), (KRF-2008314-C00223 to G. L.) and 2008 grant from Department of Medical Sciences, The Graduate School, Ajou University (K. C.).

\section{References}

1. Misu, Y.; Kitahama, K.; Goshima, Y. Pharmacol. Ther. 2003, 97, 117.

2. Oeltmann, T.; Carson, R.; Shannon, J. R.; Ketch, T.; Robertson, D. Auton. Neurosci. 2004, 116, 1.

3. Tsunoda, M. Anal. Bioanal. Chem. 2006, 386, 506.

4. Rodgers, K. J.; Dean, R. T. Int. J. Biochem. Cell Biol. 2000, 32, 945 .

5. Vieira-Coelho, M. A.; Pestanat, M.; Soares-da-Silva, P. Gen. Pharmac. 1996, 27, 1421.

6. Sagar, K. A.; Smyth, M. R. J. Pharm. Biomed. Anal. 2000, 22, 613.

7. Viswanathan, S.; Liao, W. C.; Huang, C. C.; Hsu, W. L.; Ho, J. A. Talanta 2007, 74, 229.

8. Blandini, F.; Martignoni, E.; Pacchetti, C.; Desideri, S.; Rivellini, D.; Nappi, G. J. Chromatogr. B Biomed. Sci. Appl. 1997, 700, 278.

9. Letellier, S.; Garnier, J. P.; Spy, J.; Bousquet, B. J. Chromatogr. B Biomed. Sci. Appl. 1997, 696, 9.

10. Tolokán, A.; Klebovich, I.; Balogh-Nemes, K.; Horvai, G. J. Chromatogr. B Biomed. Sci. Appl. 1997, 698, 201.

11. Saxer, C.; Niina, M.; Nakashima, A.; Nagae, Y.; Masuda, N. J. Chromatogr. B 2004, 802, 299.

12. Tornkvist, A.; Sjoberg, P. J.; Markides, K. E.; Bergquist. J. J. Chromatogr. B 2004, 801, 323.

13. Gu, Q.; Shi, X.; Yin, P.; Gao, P.; Lu, X.; Xu, G. Anal. Chim. Acta 2008, 609, 192.

14. Igarashi, K.; Hotta, K.; Kasuya, F.; Abe, K.; Sakoda, S. J. Chromatogr. B 2003, 729, 55. 
15. Li, W.; Rossi, D. T.; Fountain, S. T. J. Pharm. Biomed. Anal. 2000, 24,325 .

16. Jiang, W.; Lv, L.; Zhou, S.; Huang, X.; Shi, X.; Lv, C.; Wu, L.; Xu, C. J. Pharm. Biomed. Anal. 2010, 53, 751.

17. Gal, J.; Ames, M. M. Anal. Biochem. 1977, 83, 266.

18. Mizuno, Y. Clin. Chim. Acta 1977, 74, 11.

19. Macfarlane, R. G.; Midgley. J. M.; Watson, D. G.; Evans, P. D. J. Chromatogr. B 1990, 532, 1.

20. de Jong, A. P.; Kok, R. M.; Cramers, C. A.; Wadman, S. K.; Haan,
E. Clin. Chim. Acta 1988, 171, 49.

21. Paik, M. J.; Kim, K. R. J. Chromatogr. A 2004, 1034, 13.

22. Paik, M. J.; Lee, H. J.; Kim, K. R. J. Chromatogr. B 2005, 821, 94.

23. Paik, M. J.; Moon, S. M.; Kim, K. R.; Choi, S.; Ahn, Y. H.; Lee, G. Biomed. Chromatogr. 2008, 22, 339.

24. Turler, K.; Kaser, H. Clin. Chim. Acta 1971, 32, 41.

25. Blau, N.; Rosenmund, H. Clin. Chim. Acta 1977, 75, 213.

26. Selmaoui, B.; Aymard, N.; Lambrozo, J.; Touitou, Y. Life. Sci. 2003, 73, 3073 . 